\section{Scientific Publication during PhD Candidature: Preclinical versus Clinical Research}

\section{DOI: $10.1515 / \mathrm{rrlm}-2016-0016$}

Nowadays, the research dissemination form preferred by most scientists is publication in peer-reviewed journals (1). A list of publications is considered proof of core research skills and an indicator for future achievements (2). The motives behind publication may vary from improving clinical practice, patients' well being, furthering career ambition to academic reputation for researchers, while for editors and publishers the motives may vary from altruistic to commercial ones (3).

Medical research is fundamental in generating the evidence needed to improve healthcare. According to scientific literature, challenges in the preclinical and clinical research domain refer to research transparency, publication bias, dissemination and accessibility of results and the gap between research and practice. Failure to disseminate research result, positive or negative, adds to the publication bias affecting the relevance of published results of other trials and the utility of Systematic Reviews and Meta-analyses (4).

So far, publication of medical $\mathrm{PhD}$ results has been significantly associated with gender, enrollment age, field of undergraduate training, thesis topic area, thesis completion on time and thesis score. The barriers to publishing results related with medical research were the increased workload, insufficient tutor support, publication bias for negative results, insufficient motivation and family burden (1).
The increasing competitiveness in science and academia regarding expectations to publish has extended to $\mathrm{PhD}$ candidates as well (5). Graduate students' publication rates have enhanced significantly over time, in some cases before PhD completion (6), probably due to the increased expectations of doctoral programs. Studies on scientific publishing during PhD candidature have proved it develops scientific and academic skills, enhances researcher's visibility, and can be used as a predictor for grant proposal acceptance and future career success (7).

Of all the studies aimed at assessing $\mathrm{PhD}$ publication production in the medical field, few evaluated the research type undertaken by $\mathrm{PhD}$ students and no studies compared research publications from $\mathrm{PhD}$ theses with preclinical and clinical research topics. This type of information could be used by supervisors and future $\mathrm{PhD}$ candidates for deciding on the type of research topic. We wanted to check if scientific dissemination of thesis-related results presented any difference when comparing preclinical research to clinical research from medical PhDs.

"Iuliu Haţieganu" University of Medicine and Pharmacy, considered one of the best and largest Romanian medical universities, was chosen as representative. Its intranet network provided the full-text medical $\mathrm{PhD}$ theses defended in 2009-2013. We collected the following data: author initials, thesis title, completion date, total number of articles published or accepted for publication during $\mathrm{PhD}$ candidature, number of supervisors (to estimate the scientific aid a $\mathrm{PhD}$ candidate received during $\mathrm{PhD}$ candidature), and thesis length in pages (with/without References and Appendix sections). Based on the thesis author's statement regarding thesis-related published papers (presented in a list or in the thesis 
text, either appended at the end of the thesis or in the Reference section of the thesis) the number of articles related to each thesis was established. We did not search for articles beyond the date of thesis completion and did not use textual analysis due to its limitations.

The theses were split into two groups according to preclinical and clinical research topics and were compared regarding thesis length, article counts, and the number of supervisors. Moreover, the article's groups were compared regarding: the number of authors, the $\mathrm{PhD}$ graduate being the first author, authors' affiliation (just Romanian or combination of Romanian and foreign), and journal regional address (Romanian or foreign journal), and journal rank based on the impact factor (IF) from Journal Citation Reports in the year when the article was published (according to journals split into quartiles: Q1 to Q4). The data was provided by the thesis full-texts, Web of Science (WOS), Journal Citation Reports and the journal official web-sites or NLM Catalog. We also collected the number of citations from all Web of Science databases for each article (searched on $1^{\text {st }}$ November 2015). Counts and percentages were used for qualitative data, as well as Z-test for proportions for comparing groups. Median and inter quartile range (the $25^{\text {th }}$ percentile (Q1) the $75^{\text {th }}$ percentile (Q3)) were used for quantitative data as central tendency and dispersion indicators since data proved not normally distributed, while comparison between groups was done using the Mann-Whitney-U test. Statistical analysis was performed with Statistica software (v. 8.0), where the two-tailed p-values were used at a significance level of 0.05 .

Our preclinical research (PCR) group consisted of 78 theses, which included 194 thesis-related articles. The clinical research (CR) group consisted of 347 theses, which included 827 thesis-related articles.
The PCR group presented significantly larger theses and a higher number of supervisors than the CR group. No significant difference between the numbers of thesis-related articles from PCR and CR groups was identified, as they belong to the same university (see Table 1a). However, the PCR group published significantly more articles in international scientific journals than those from the CR group, most of the CR group articles being published in Romanian journals (Table 1b). The median number of authors per article was 4 for both groups without significant difference $(p=0.150)$. Regarding article indexation, out of all the thesis-related articles only $25.47 \%$ were listed in WOS Core Collection (ISI articles) and just $17.92 \%$ were published in journals with IF. The theses from the two groups presented similar counts of thesis-related ISI articles (Table 1a).

Considering that our study has found 260 $\mathrm{PhD}$ thesis-related ISI articles in a single Romanian medical institution, the case of Romania seems to have improved since 2007, when a survey on all medical ISI articles published by Romanian scholars between 1997 and 2006 reported 907 articles (an amount 120 times less than that from France, 6.59 times less than that from Hungary, and 1.17 times less than that from Bulgaria) (8).

We did not consider relevant to compare the PCR and CR groups using the IF as the IF differs significantly from discipline to discipline (9), the articles having been published in journals from various medical categories according to ISI classification. Thus, as a means to balance out the IF, we analyzed journal ranks for all thesis-related ISI articles (according to Journal Citation Reportsonly journals with IF). Almost $20 \%$ of the thesis-related articles published by $\mathrm{PhD}$ students from the PCR group were found in top journals $(\mathrm{Q} 1)$, this percentage being signifi- 
cantly higher compared with $9.02 \%$ from the CR group $(p$-value $=0.042)$. There were no significant differences comparing the PCR and $\mathrm{CR}$ groups regarding the percentage of thesis-related articles published in Q2, Q3 and $\mathrm{Q} 4$, respectively ( $\mathrm{p}$-values $>0.05$ ). Publishing in top journals can be daunting as they focus on the most important research results in an attempt to reach the widest audience possible and to maximize their profits (10), their selectiveness leading to increased rejection rates, possibly up to $80-90 \%$ of submissions (2).

Half of the articles belonging to PCR had at least 6 citations while half of those from CR had at least 3 citations $(p<0.05)$. Citation analysis based on the article age highlighted that PCR gain more citations than $\mathrm{CR}$ as time passes and articles age (see Table 1b). Collaboration with at least one researcher of foreign affiliation was not statistically different when all PCR thesis-related ISI articles (39.34\%) were compared with the CR ones (31.97\%) (see Table 1b). While focusing just on the percentage of thesis-related articles published by Romanian affiliated authors, no significant differences were observed comparing the PCR and $\mathrm{CR}$ groups with regard to publication in Q1, Q2, Q3 and Q4 rank journals, respectively ( $\mathrm{p}$-values $>0.35$ ).

Next, we checked for each group the correlations between citations and each of the following variables: the number of article authors, journal Q-Rank, article publication year, the collaboration with an author with foreign affiliation. Just for the PCR group, collaboration with an author with foreign affiliation positively correlated with the number of citations (Spearman $\rho=0.529$, $\mathrm{p}<0.001)$. Furthermore, as expected, a high negative correlation coefficient between the number of citations and journal Q-ranking $(\rho=-0.588$, $\mathrm{p}<0.001$ ) was observed in the PCR group. A similar result was observed in the CR group, but with a lower correlation coefficient (citations\& journal Q-rank: $\rho=-0.247, p=0.006$ ). A possible explanation for this difference could be found in the number of ISI articles and/or h-index of tutors. However, such analysis needs a proper sample to allow generalization of results and it is under investigation.

The need for publishing together with an author affiliated outside of Romania could be explained by recent studies in peer-review bias (11), and publishing with a foreign author could help solve the nationality bias issue.

Table 1a. Quantitative analysis of thesis related aspects in the preclinical research and clinical research groups

\begin{tabular}{lccc}
\hline Item & $\begin{array}{c}\text { Preclinical research } \\
\mathbf{n = 7 8}\end{array}$ & $\begin{array}{c}\text { Clinical research } \\
\mathbf{n = 3 4 7}\end{array}$ & p-value \\
\hline Thesis pages without references and appendix & $139(114-189)$ & $129(107-166)$ & $0.034^{*}$ \\
\hline All thesis pages & $159.5(133-207)$ & $144(118-184)$ & $0.018^{*}$ \\
\hline Number of thesis contributors & $1(1-1)$ & $1(1-1)$ & $0.011^{*}$ \\
\hline $\begin{array}{l}\text { All articles published or accepted for publication } \\
\text { during PhD candidature }\end{array}$ & $2(1.75-3)$ & $2(1-3)$ & $0.483^{*}$ \\
\hline Number of ISI articles with impact factor per thesis & $0(0-1)$ & $0(0-0)$ & $0.019^{*}$ \\
\hline $\begin{array}{l}\text { Data are expressed as median and (Q1-Q3) } \\
\text { Q1 }=25^{\text {th }} \text { percentile; Q3 }=75^{\text {th }} \text { percentile; WOS }=\text { Web of Science; }\end{array}$ & & \\
$*$ Mann-Whitney-U test & & & \\
\hline
\end{tabular}


This analysis included theses from just one Romanian university and evaluated only articles published until $\mathrm{PhD}$ completion. Future research should evaluate more Romanian universities. In the context of publication pressure, medical PhD candidates could choose a preclinical research topic if they hope for good visibility of their research, and could collaborate with foreign researchers to increase their chances to publish their research output in highly ranked journals.

\section{Conflict of interest}

The authors declare that there are no conflicts of interest.

\section{Table 1b. Quantitative analysis of thesis related articles in the preclinical and clinical research groups}

\begin{tabular}{|c|c|c|c|c|c|}
\hline Item & \multicolumn{2}{|c|}{ Preclinical research } & \multicolumn{2}{|c|}{ Clinical research } & p-value \\
\hline \multicolumn{6}{|c|}{ Theses-related articles: $f(\%)$} \\
\hline PhD graduate is first author of the article & $\mathrm{n}=194$ & $150(77.3 \%)$ & $\mathrm{n}=827$ & $721(87.2 \%)$ & $0.001 * *$ \\
\hline $\begin{array}{l}\text { At least one author has affiliation out- } \\
\text { side of Romania }\end{array}$ & $\mathrm{n}=194$ & $44(22.7 \%)$ & $\mathrm{n}=827$ & $110(13.3 \%)$ & $0.001 * *$ \\
\hline Article published in Romanian journals & $\mathrm{n}=194$ & $152(78.4 \%)$ & $\mathrm{n}=827$ & $726(87.8 \%)$ & $0.001 * *$ \\
\hline $\begin{array}{l}\text { Article is ISI: } \\
\text { Foreign journals } \\
\text { Romanin journals }\end{array}$ & $\begin{array}{c}n=194 \\
n=69\end{array}$ & $\begin{array}{l}69(35.57 \%) \\
31(44.92 \%) \\
\end{array}$ & $\begin{array}{l}n=827 \\
n=191\end{array}$ & $\begin{array}{c}191(23.1 \%) \\
111(58.11 \%)\end{array}$ & $\begin{aligned}< & 0.001 * * \\
& 0.060\end{aligned}$ \\
\hline $\begin{array}{l}\text { Article is ISI with impact factor: } \\
\text { Foreign journals } \\
\text { Romanian journals }\end{array}$ & $\begin{array}{c}n=194 \\
n=61\end{array}$ & $\begin{array}{l}61(31.44 \%) \\
25(40.98 \%)\end{array}$ & $\begin{array}{l}\mathrm{n}=827 \\
\mathrm{n}=122\end{array}$ & $\begin{array}{c}122(14.75 \%) \\
58(47.54 \%)\end{array}$ & $\begin{aligned}< & 0.001 * * \\
& 0.402\end{aligned}$ \\
\hline \multicolumn{6}{|l|}{$\begin{array}{l}\text { Article is ISI and at least one author has } \\
\text { affiliation outside of Romania: }\end{array}$} \\
\hline $\begin{array}{l}\text { ISI journal rank: } \\
\text { Q1 } \\
\text { Q2 } \\
\text { Q3 } \\
\text { Q4 }\end{array}$ & $\mathrm{n}=61$ & $\begin{array}{l}12(19.67 \%) \\
9(14.75 \%) \\
14(22.95 \%) \\
26(42.62 \%) \\
\end{array}$ & $\mathrm{n}=122$ & $\begin{array}{l}11(9.02 \%) \\
24(19.67 \%) \\
35(28.69 \%) \\
52(42.62 \%) \\
\end{array}$ & $\begin{array}{r}0.042 \\
0.398 \\
0.399 \\
>0.99 \\
\end{array}$ \\
\hline \multicolumn{6}{|c|}{ Citations of theses-related ISI with impact factor articles: Median (Q1-Q3) } \\
\hline $\begin{array}{l}\text { Total of article citations from all WOS } \\
\text { databases }\end{array}$ & $\mathrm{n}=61$ & $6(2-13)$ & $\mathrm{n}=122$ & $3(1-6.75)$ & $0.003 *$ \\
\hline $\begin{array}{l}\text { Citations from all WOS databases for } \\
\text { articles published between: } \\
2008-2011 \\
2012-2013\end{array}$ & $\begin{array}{l}n=37 \\
n=24\end{array}$ & $\begin{array}{l}8(2.5-18.5) \\
3.5(2-8.5)\end{array}$ & $\begin{array}{l}n=70 \\
n=52\end{array}$ & $\begin{array}{l}3.5(1-9) \\
2(1-5)\end{array}$ & $\begin{array}{l}0.020^{*} \\
0.050^{*}\end{array}$ \\
\hline
\end{tabular}




\section{Andrada Elena Urda-Cîmpean', Sorana Daniela Bolboacă ${ }^{1, *}$, Andrei Achimaş- Cadariu $^{1}$, Tudor Cătălin Drugan ${ }^{1}$}

\section{Department of Medical Informatics and Biostatistics, Iuliu Haţieganu University of Medicine and Pharmacy Cluj-Napoca, Romania.}

* Corresponding author: Sorana Daniela Bolboacă, e-mail: sbolboaca@umfcluj.ro

Received: 27th January 2016; Accepted: $13^{\text {th }}$ April 2016; Published: $27^{\text {th }}$ May 2016.

\section{References}

1. Hollmann M, Borrell C, Garin O, Fernández E, Alonso J. Factors influencing publication of scientific articles derived from masters theses in public health. Int J Public Health. 2015;60(4):495-504. DOI: 10.1007/ s00038-015-0664-0.

2. Bartkowski JP, Deem CS, Ellison CG. Publishing in Academic Journals: Strategic Advice for Doctoral Students and Academic Mentors. Am Sociol. 2015;46(1):99-115. DOI: 10.1007/s12108-0149248-3.

3. Coomarasamy A, Gee H, Publicover M, Khan KS. Medical journals and effective dissemination of health research. Health Info Libr J. 2001;18:18391. DOI: 10.1046/j.1471-1842.2001.00349.x DOI: 10.1046/j.1365-2532.2001.00349.x.
4. Malički M, Marušić A. Is there a solution to publication bias? Researchers call for changes in dissemination of clinical research results. J Clin Epidemiol. 2014;67(10):1103-10. DOI: $\quad 10.1016 /$ j.jclinepi.2014.06.002.

5. Lee A, Kamler B. Bringing pedagogy to doctoral publishing. Teach Higher Educ. 2008;13(5):511-23. DOI: $10.1080 / 13562510802334723$.

6. Pinheiro D, Melkers J, Youtie J. Learning to play the game: Student publishing as an indicator of future scholarly success. Technol Forecast Soc Change. 2014;81:56-66. DOI: 10.1016/j.techfore.2012.09.008.

7. McGrail M, Rickard C, Jones R. Publish or perish: a systematic review of interventions to increase academic publication rates. High Educ Res Dev. 2006;25(1):1935. DOI: $10.1080 / 07294360500453053$.

8. Dragoş C, Dragoş S. O evaluarestatistica a pozitieiRomaniei in Europa privindpublicarea in reviste ISI. Rev Polit Stiint Sci. 2007;3:130-3.

9. Gu J, Lin Y, Vogel D, Tian W. What are the major impact factors on research performance of young doctorate holders in science in China: A USTC survey. High Educ. 2011;62(4):483-502. DOI: 10.1007/s10734-010-9400-0.

10. Salager-Meyer F. Scientific publishing in developing countries: Challenges for the future.J English Acad Purp. 2008;7(2):121-32. DOI:10.1016/j. jeap.2008.03.009 DOI: 10.1016/j.jeap.2008.03.009.

11. Lee CJ, Sugimoto CR, Zhang G, Cronin B. Bias in peer review. J Am Soc Inf Sci. 2013;64:2-17. DOI: 10.1002/ asi. 22784 . 